\title{
Production Occupations
}

National Cancer Institute

\section{Source}

National Cancer Institute. Production Occupations. NCI Thesaurus. Code C97642.

A class of professional or vocational positions of employment that involve production. 